\title{
Pain in the air: successful computed tomography-guided aspiration in a case of spontaneous pneumorrhachis
}

\author{
Farhana E. Suleman, MB ChB, FCRad(D)SA, MMED Rad(D)Medunsa ${ }^{a}$, Mark D. Velleman, MB \\ ChB, FCRad(D)SA, MMED Rad(D)UP \\ ${ }^{a}$ Radiology Department, University of Pretoria, PO Box 13044, Laudium, Pretoria 0037, South Africa \\ ${ }^{\mathrm{b}}$ Radiology Department, Little Company of Mary Medical Centre, PO Box 11315, Silver Lakes, Pretoria \\ 0054, South Africa
}

Spontaneous pneumorrhachis (air in the spinal canal) occurs in the absence of medical procedures, trauma, or free air distributions in other body compartments (such as pneumomediastinum or pneumothorax) [1]. One postulated cause is the migration of air from the disc into the spinal canal and neural foramina [1] and [2]. A 46-year-old man presented with severe, debilitating pain down the right leg after trivial trauma. Magnetic resonance imaging showed typical degenerative changes of the lumbar spine with narrowing of the L5/S1 disc space and vacuum phenomenon of the disc. A tubular pocket of air was seen in the right lateral recess and exit foramen of L5/S1 with smaller air pockets in the spinal canal posterior to the L5/S1 disc (Fig. 1). A computed tomography scan confirmed air in the right neural foramen and spinal canal (Fig. 2). Under computed tomography guidance, a 20-gauge spinal needle was inserted into the neural foramen, and the air was aspirated (Fig. 3). The patient experienced instant relief, which was maintained at 6-month follow-up.

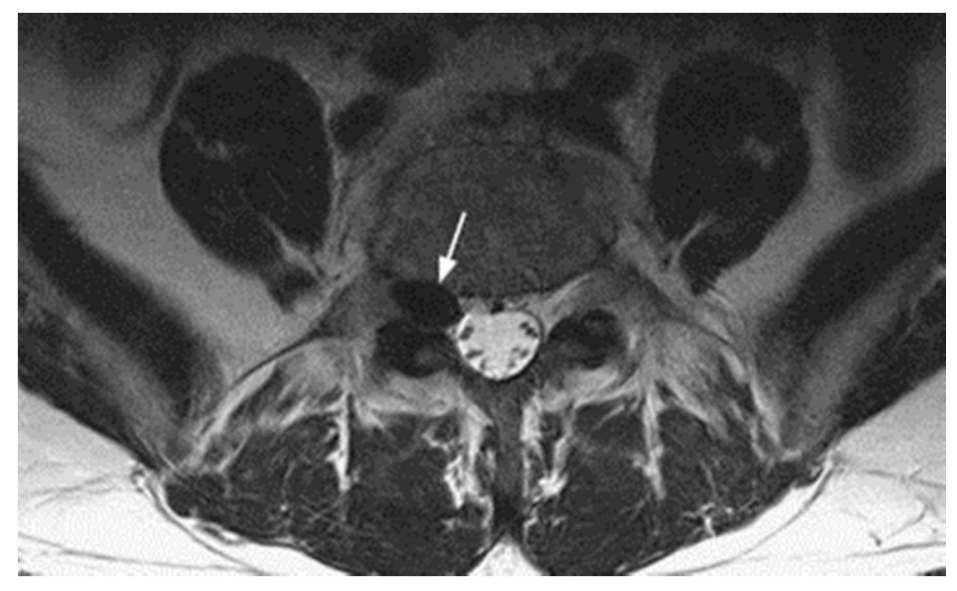

Fig. 1. Axial T2W magnetic resonance image at the level of L5/S1 neural foramen demonstrates a pocket of air in the right neural foramen (arrow). 

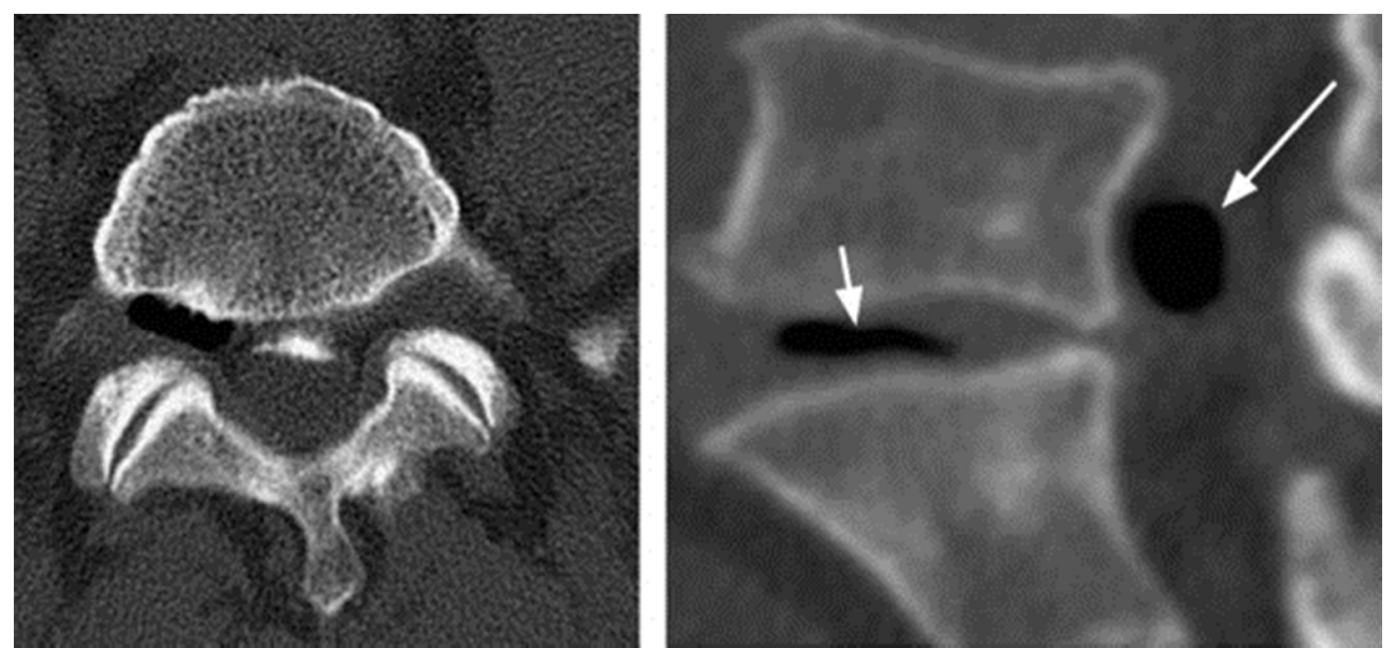

Fig. 2. (Left) Axial computed tomography (CT) scan in bone window at the level of the right neural foramen demonstrates air in the right neural foramen. (Right) Parasagittal CT image in bone window demonstrates air in the spinal canal (long arrow) and vacuum disc (short arrow).
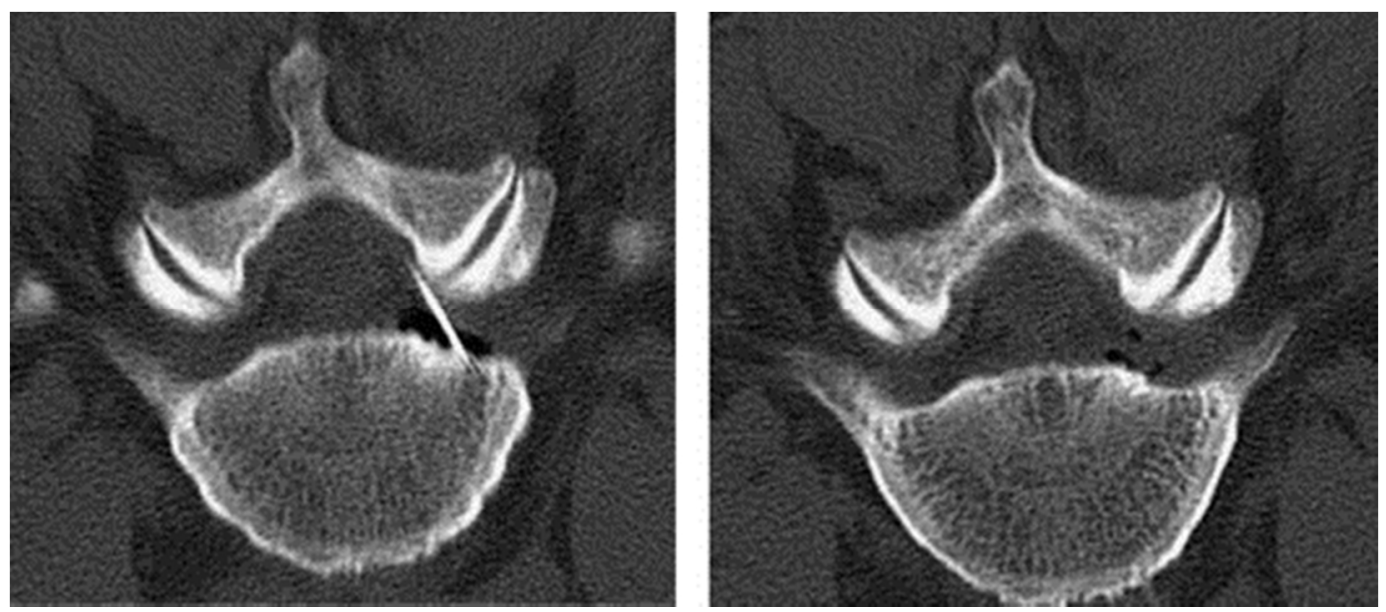

Fig. 3. Axial computed tomography scan in the bone window with the patient in the prone position demonstrates the position of the needle in the air pocket (Left) just before aspiration and (Right) immediately after aspiration.

\section{References}

1. Kim C.H. Pneumorrhachis and paraspinal air with vacuum disc: case report and literature review. J Korean Neurosurg Soc, 42 (2007), pp. 490-491

2. Kumuran, S.P., Gupta, K. Singh, S.S. A rare association of spontaneous pneumorrhachis with spondylolisthesis and lumbosacral vacuum phenomenon: a case report with review of literature. Neurol India, 59 (2011), pp. 120-121 